\title{
A Esfinge Comunal: Um Diálogo Histórico Com A Comuna De Paris
}

\author{
The Communal Sphinx: A Historical Dialogue With The Paris \\ Commune
}

Fábio José de Queiroz

Universidade Regional do Cariri (URCA)

Resumo: Propõe-se, neste artigo, examinar o fenômeno da Comuna de Paris que, 150 anos depois de sua eclosão no tablado da história, volta a ser objeto de estudo. Busca-se, assim, analisar o seu significado específico como episódio histórico e a sua contribuição para o movimento operário internacional e, sempre em estreito diálogo com a produção historiográfica marxista e as exigências e particularidades da época contemporânea, constatar os possíveis nexos entre passado e presente no âmbito das tradições socialistas.

Palavras-chave: Comuna de Paris; 150 anos; Movimento Operário; Lutas Sociais.

Abstract: This article proposes to examine the phenomenon of the Paris Commune, which 150 years after its appearance on the stage of history, is once again the object of study. It seeks to analyze its specific meaning as a historical episode and its contribution to the international labor movement and, always in close dialogue with the Marxist historiographical production and the demands and particularities of the contemporary period, to verify the possible links between past and present in the context of socialist traditions.

Keywords: Paris Commune; 150 years; Labor Movement; Social Struggles.

\section{INTRODUÇÃO}

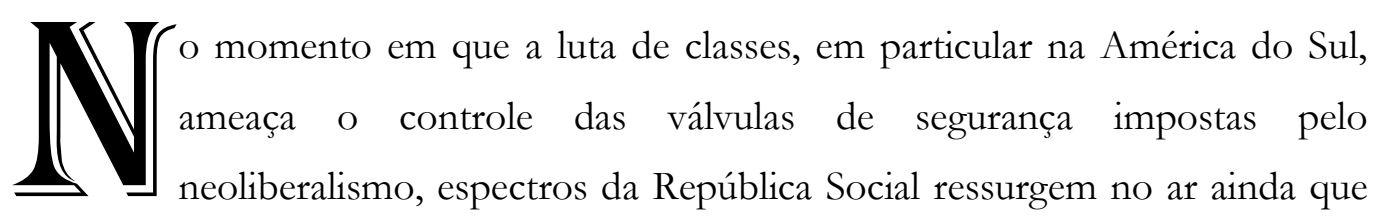

Cadernos GPOSSHE On-line, Fortaleza, v. 4, n. Único, 2021. 
debaixo de múltiplas dificuldades. República Social remete o olhar do historiador ao significado da Comuna de Paris 150 anos depois de sua irrupção e posterior aniquilamento.

Esse encontro entre o passado e o presente, entre a velha comuna e os sonhos comunitários/coletivos, uma vez mais, inspira e move as massas populares que revivem a esfinge, que não só reaparece, mas atormenta, outra vez, o espírito burguês.

Neste artigo, reconstituo a experiência da Comuna de Paris, ao passo que, à luz dos conflitos sociais em curso no mundo, especialmente no continente sul-americano ${ }^{1}$, estabeleço possíveis liames entre o primeiro governo operário da história e os desafios de um proletariado que vive sob os auspícios e os dilemas de um tempo em que a consciência socialista sofreu um virtual retrocesso no rastilho da queda dos Estados Operários do leste.

A ideia de abordar o tema, uma vez mais, decorre não só da efeméride relativa aos 150 anos da experiência comunal parisiense, mas da necessidade de reexaminar as soluções coletivas no âmbito da classe trabalhadora, tomando como referência (1) o lugar do primeiro governo operário na história do movimento socialista internacional, (2) o retrocesso da consciência política para antes da situação que ensejou a Comuna e a Revolução Russa e (3) a necessidade de reerguer o projeto operário e socialista como método, programa e estratégia.

Dito isso, a história das experiências socialistas como campo específico de estudo é algo que me move no terreno da pesquisa histórica, notadamente na perspectiva de trazê-la para o plano de um diálogo com o contemporâneo. De plano, ressalta-se uma questão: qual o sentido de propor tal diálogo? No instante em que as massas populares retomam seu protagonismo nas ruas, nomeadamente "en las calles" da América do Sul, em meio à catástrofe da Covid-19, parece-me bastante pertinente tentar estabelecer liames entre a tradição dos projetos coletivos de uma nova sociedade, a chamada República Social, e a ausência de um horizonte estratégico nítido no terreno das mobilizações em curso.

Não se trata de ressuscitar uma época morta, até porque a época de domínio do capitalismo imperialista permanece como a pergunta que precisa ser respondida: o que fazer com ela? Acatar ou desafiar esse domínio? No átimo de tempo em que a ordem do capital é desafiada nas ruas, sem que as lutas correntes se sustentem na nitidez de um projeto de superação da ordem social capitalista, retomar a experiência do primeiro governo operário da história não vem a propósito?

\footnotetext{
${ }^{1}$ Depois de mais de um ano de pandemia, ligada à Covid-19, parece dominar o espírito das massas sulamericanas a ideia de que quando os seus governantes são piores do que o vírus, justifica-se sair às ruas em protesto.
} 
Parafraseando Marx (1997), não se trata de tomar emprestado a linguagem, as paixões e as ilusões dos velhos communards, mas de recuperar a estratégia e o método de luta por um governo operário e popular. Até porque, uma vez mais dialogando com o velho Marx, a revolução do século XXI não pode tirar sua poesia do passado. No entanto, para que a revolução não tenha vida curta ou sofra um desvio na primeira aresta, ela precisa aprender com os acertos e os erros do passado. Nesse sentido, revisitar a Comuna de Paris é uma exigência até histórico-pedagógica.

Metodologicamente, como pode se perceber ao longo deste trabalho, a revivescência a que me atenho se faz por meio de uma interlocução com parte relevante da produção historiográfica acerca da Comuna de Paris, tomando como eixo nevrálgico o clássico livro de Marx, Guerra civil em França, avançando para produções mais recentes que objetivam dar conta desse fato. Concomitantemente, considero um breve exame dos conflitos de classe em trânsito que, em parte, acompanho como integrante das lutas sociais e militante socialista, sem, contudo, invocar uma literatura específica a esse respeito até por se tratar de um processo em fluxo.

Por fim, tendo a pensar que a retomada desse debate avigora o esforço de intelectuais e militantes da causa socialista que não desprezam as probabilidades que decorrem das conexões entre pesquisa histórica, apoiada em evidências, e as lutas sociais que em tempos de fake news, mais que antes, carecem de luminosidade e lucidez no plano das ciências.

\section{PEQUENOS COMENTÁRIOS A RESPEITO DA COMUNA DE PARIS}

Ao contrário de certos historiadores que julgam desnecessário recontar a história da Comuna de Paris, cogito que seja indispensável reconstituir os fatos fundamentais que a construíram, considerando que, em relação a eles, muitas vezes, a memória antiga falha e a nova ignora.

No dia 9 de setembro de 1870, a França foi derrotada pela Prússia. A história registrou esse fato como a Capitulação de Sedan. Luís Bonaparte III foi preso e abriu-se o caminho para restauração do regime republicano. Começava a III República. Nesse contexto, é fundamental o papel desempenhado pela Guarda Nacional, formada majoritariamente de operários. Conquistando Paris, essa guarda especial descortinará o horizonte para o estabelecimento do primeiro governo operário da história.

Para entender essa conquista do proletariado parisiense, é preciso recordar que no dia 18 de março de 1871, quase de chofre, o primeiro mandatário da recém-instalada III 
República decidiu desarmar a Guarda Nacional em Paris. Os operários em armas rechaçaram a manobra de Thiers, o novo chefe de governo. Começava uma experiência na qual a "vil multidão", para usar um termo recorrentemente usado pelos agrupamentos dominantes da época, apossou-se do leme e passou a governar a capital francesa. Em seus desdobramentos, o ponto de inflexão mais importante era a edificação do governo da Comuna - por volta do dia 26 de março de 1871- que, nas palavras de Marx, "quebra o moderno poder de Estado” (2008, p. 405). Essa experiência se prolongaria - no limite - até 28 de maio daquele ano, mas "a esfinge que atormenta o espírito burguês", como diria Marx (2008, p. 398), volta e meia reaparece como uma ameaça ao controle das classes detentoras dos meios de produção.

Assim, 150 anos depois, não somente na França, mas no mundo inteiro, esse experimento que ousou enfrentar a "máquina de desportismo de classe" foi saudado, estudado e enriquecido em suas interpretações, lembrando que a historiografia marxista, em geral, tomou esse fato como "o grande antecedente e o grande exemplo a ser seguido e, ao mesmo tempo, criticado" (COGGIOLA, 2002, P. 7). Decerto, o presente não pode mudar o passado, mas pode jogar luz sobre os acontecimentos que o constituíram, dando vazão a um novo leque de entendimentos acerca dos fatos e dos sujeitos a eles relacionados.

Em um momento em que se desenvolve um conjunto de investigações historiográficas centradas nas noções de "História de baixo pra cima" e "História dos excluídos", parece-me de bom tom recuperar esse episódio que diz respeito à vida dos que pertencem ao campo dos que que nada têm a perder, mas um mundo a ganhar.

Marx (2008), em A guerra civil na França, estabeleceu uma primeira interpretação do significado histórico das ações protagonizadas pelos insurgentes parisienses, estabelecendo uma generalização teórica dos fatos históricos, consoante escreveu Engels (2008) na introdução à obra antes citada. Trata-se, agora, de observar não apenas a atualidade da análise concreta da situação concreta, mas de ligar os acontecimentos concretos que serviram de arrimo aos estudos marxianos e o período presente com as suas exigências de uma iminente atualização política e historiográfica.

Vale a pena discutir o que a Comuna do século XIX pode oferecer aos comunards do século XXI. Essa questão decorre de um problema que lhe é anterior: o que foi a Comuna de Paris? Desse modo, nos próximos itens, a intenção é organizar uma reflexão que dê conta dessas duas problemáticas que se resumem a uma tentativa de estudar a interpenetração histórica entre passado e presente. 
Em síntese: trata-se, simultaneamente, de estabelecer um mirante privilegiado a partir do qual se pode apreciar a luta política da classe operária e abrir novas trilhas para o seu estudo, evocando e mobilizando o exemplo da Comuna de Paris. Os 150 anos do fato traduzem um impulso e uma provocação aos historiadores escolados na tradição marxista.

\section{DIÁLOGO COM A HISTORIOGRAFIA}

Paris: a cidade cercada. Em sua estrutura interna, uma massa de homens e mulheres, nas palavras de Marx (2008), desafiou “a máquina de guerra nacional do capital contra o trabalho (p. 400), rompendo com o cerco da máquina do Estado e a sujeição social que lhe era própria. Ao longo da história, as classes dominantes e os seus ideólogos mantiveram esse cerco no campo das Ciências Humanas, assédio que, com frequência, é desafiado por historiadores que instituem pontos de referência para o embate contra o empenho dos primeiros com vistas a sepultar a memória dos vencidos.

A história é uma arena profana de conflitos, de disputas e não um espaço venerado e monolítico. Há uma variedade de pontos de vista, de ideologias e de interesses que se rivalizam e que se contestam. Os derrotados - de ontem e de hoje - carecem ser ouvidos e devem fazer desse anelo a sua regra de ouro.

É importante reter que a história da Comuna de Paris respinga luta de classes e que essa categoria social, apesar da tenaz resistência de uma camada de pensadores sociais, a exemplo de Chauvel (2002), segue censurada e tomada como descabida nos principais santuários da academia. Não é de estranhar que esse procedimento-padrão do mundo acadêmico resvala igualmente para o termo revolução que, em conformidade com uma leitura hegemônica no campo intelectual, deveria ser afogado em águas geladas. Nesse sentido, convêm lembrar que a Comuna, por numerosas razões, sugere um resgate de conceitos como os de luta de classes e revolução.

Em relação a esse quadro, a Comuna de Paris - com os seus tipos, rostos, frases, costumes e cenas - é resultante de um processo revolucionário em que a luta de classes se elevou a um grau máximo de intensidade. Aqui, desde já, uma questão se impõe: encerraria esse desenho panorâmico, nos dias de hoje, algum nível de atualidade?

Ferlini (1998) afirma que "mais que mito, a revolução é um dado concreto da História e um elemento central do saber histórico” (p. 185). Doutro lado, não há nada mais extraordinário do que a explosão de um processo revolucionário. As revoluções não são situações regulares, mas extraordinárias. São precisamente esses aspectos - ser um dado 
concreto da história, ser um elemento do saber histórico e representar momentos de excepcionalidade na trajetória humana - que autoriza o reconhecimento do conceito de revolução como indispensável ao métier do historiador.

Assim sendo, de plano, reitero a atualidade dos estudos que gravitam em torno das ideias de luta de classes e revolução. Desse ponto de vista, a experiência dos communards parisienses encerra em seu ato toda uma vivíssima atualidade, ainda que se deva entender que o tratamento desse problema depende soberanamente da postura de cada historiador, de como ele percebe o mundo e se localiza social e ideologicamente.

No átimo dos acontecimentos - diferentemente de intelectuais como Nietzsche e Flaubert - Marx procurou não somente analisar os acontecimentos, mas, em ato contínuo, buscou exortar o apoio dos trabalhadores do mundo aos operários parisienses. Apesar de rápida, a análise de Karl Marx se tornou referência e, ao longo do tempo, viu-se ratificada e refutada por diferentes correntes do pensamento social.

Nessa perspectiva, o resultado da observação vigilante de Marx é uma rica contribuição aos estudos sobre a classe operária e o seu papel ativo na sociedade moderna, leia-se: capitalista. Em sua leitura dos fatos, como já antevisto, a Comuna aparece como uma espécie de esfinge que atormenta o espírito burguês; mas o velho alemão não deixou de abordar o tema dialeticamente e, nesse movimento, ele vislumbrou as suas possibilidades e limites e a definiu como "governo possível num tempo em que a burguesia já tinha perdido a faculdade de governar a nação e a classe operária ainda não a tinha adquirido” (2008, p. 401). Além disso, demarcou-a essencialmente na condição de um governo da classe operária. Por fim, acresceu que os operários compreenderam que a sua emancipação dependeria de "longas lutas" e de "uma série de processos históricos que transformam circunstâncias e homens" (MARX, 2008. p. 408).

Não apenas Marx, mas quase todos que se debruçaram sobre a Comuna, concluíram que não lhe fora concedido tempo. De 18 de Março a 28 de maio de 1871, os communards tomaram o céu de assalto apenas para perdê-lo em um brevíssimo intervalo de tempo, o que, nas palavras de Lavrov, caracteriza o governo da cidade de Paris como "a aurora, ainda que pálida, da primeira república proletária”, (TROTSKI, 2011, p. 15).

O resultado - além do "morticínio em massas a sangue frio" dos membros ativos do poder operário e popular - foi a "chacina de gente inteiramente estranha à contenda", como se lê nas célebres páginas escritas por Marx (2008, p. 425), que, aliás, não deixou de demonstrar o paradoxo do poder comunal: "A moderação da Comuna durante dois meses de indiscutível preponderância só é igualada pelo heroísmo de sua defesa" 
(2008, p. 427). Por outro lado, o abismo das leituras de classe fica nítido ao se ter em mente as palavras de Thiers. Para ele, triunfou "a ordem, a justiça e a civilização" que, em linhas gerais, "alcançaram finalmente a vitória" (MARX, 2008, p 424). Ou seja: a infâmia indiæivel era transformada em triunfo da civilização.

Os pesquisadores que estudaram a fundo a obra dos pouquíssimos meses de domínio operário na Paris pré-belle époque, em geral, adotaram uma postura categoricamente favorável às medidas adotadas por seu governo provisório, dentre elas: o fim da pena de morte, a expansão do ensino público e gratuito, a revogabilidade dos mandatos públicos, a definição dos ganhos dos mandatários em estreita compatibilidade com o salário médio de um trabalhador especializado, a máxima publicização dos seus atos e a substituição da força pública especificamente armada, pelo povo em armas (BOITO JR, 2001; COGGIOLA, 2002; GONZÁLES, 1981; LIGASSARAY, 1991; MATOS, 2002; TROTSKI, 2011).

A questão imediata é que, depois de 150 anos, pode-se observar que essa é uma discussão que continua. Nem todas as perguntas foram feitas. Nessa lógica, há questões e controvérsias que os historiadores socialistas precisam retomar. Trotski (2011, p. 15) define a comuna parisiense de "ensaio histórico, débil ainda, de dominação da classe operária"; Gonzáles (1999) problematiza o significado da Comuna como forma social; Sena Júnior (2011), por seu turno, problematiza se cabe ou não a aplicação da teoria da revolução permanente de Trotski para análise da Comuna. Trata-se de um escasso leque de possibilidades que apenas ilustra o potencial de estudos em torno da experiência comunal de Paris. Em outras palavras, há múltiplos problemas que podem vir a se constituir em objeto de análises, críticas e aprofundamentos.

À primeira vista, voltar ao tema é apenas uma parte do problema. Há transações e obrigações mútuas entre o passado e o presente. Ao invés de apenas se contentar em recolocar o assunto na mesa, me parece necessário admitir a plausibilidade de o pesquisador vir a reatar os fios que permitem estabelecer um diálogo entre a Comuna e o movimento operário contemporâneo, não só para identificar os pontos comuns, mas, também, as significativas diferenças entre ambos. E não é menos flagrante a necessidade de construir novas leituras e interpretações de reminiscências que aparentam adormecidas, até porque parecem mais do que recordações entorpecidas pelo tempo.

Não se trata de uma suspeição crítica do que se escreveu acerca do tema, mas da convicção de que há possibilidades reais de explorar aspectos do objeto que seguem subexaminados e de enriquecer a história dos movimentos populares. Hobsbawm afirmava que "a maior parte da história do passado era escrita para glorificação e talvez uso prático 
dos governantes" (1998, p. 16); Marx (2008) escreveu para o uso prático dos oprimidos nas galés do capital. Apesar disso, cabe dizer que ainda não se venceu o desafio de fazer com que a história da gente comum - incluída aí a da classe operária - efetivamente decole, afrontando o conjunto de narrativas oficiais.

Os primeiros passos foram dados, mas há muito ainda a ser caminhado. A história da Comuna é parte desse horizonte em movimento. Passado um século e meio dessa experiência, em que operários da construção civil e metalúrgicos se juntaram a outras camadas do povo trabalhador com o intuito de criar "um governo do povo pelo povo", para historiadores dedicados à história da classe trabalhadora, é uma tarefa inevitavelmente atual retomar o tema, tanto pelo engajamento político como pelo compromisso em relação ao saber histórico; afinal, não está demonstrado que esses dois fatores não possam ter compatibilidade um com o outro.

\section{A COMUNA, HOJE?}

A Comuna de Paris segue como um divisor de águas, uma vez que, convém relembrar pela enésima vez, ela significou a primeira experiência, não obstante, muito breve, em que os operários tomaram nas mãos o mundo do governo e não somente $\mathrm{o}$ mundo das ruas. Não por acaso, no que se refere à Revolução Russa, os seus principais líderes, Lênin, em especial, não se recusaram a estudar os caracteres particulares desse processo, tomando-o como um ensaio precioso.

Hoje, o que temos a aprender da heroica tentativa dos comunards? Quais os elos entre presente e passado, dos operários de ontem e do tempo presente?

Tendo em vista essas questões, de pronto temos uma hipótese e uma nova questão: o que está em causa é o horizonte político do proletariado para toda uma época. Essa é a hipótese. Por sua vez, e sem embargo disso, o que haveria mudado porquanto ocorreu uma perda vertiginosa de influência do programa e da estratégia socialistas? Esse é o novo problema. Dele sobressaem não apenas novas e candentes contradições, mas novos desafios para os comunards do século XXI.

Já vão longe os tempos em que os operários se tornavam socialistas e lutavam por seu governo quase que espontaneamente (quase, pois nunca foi espontaneamente!). Houve um retrocesso da consciência socialista em um contexto de reação econômica, política, militar e ideológica do imperialismo, valendo dizer que o derradeiro decênio do século passado se constituiu no período mais característico de apavorante regresso 
histórico e declive cultural, quando o neoliberalismo se consolidou em quase todo o planeta (QUEIROZ, 2017).

A par de tais circunstâncias, é como se a consciência socialista houvesse regredido não somente a uma etapa histórica imediatamente anterior ao triunfo da Revolução Russa de 1917, mas como devesse prestar juras de amor ao cenário sociopolítico que antecedeu à heroica experiência da Comuna. Cumpre lembrar que a expressão heroica não está aqui por um desses tantos acasos da vida. Marx (2008) advertira que a Comuna de Paris era concomitantemente um governo de um lustro histórico em que nem a burguesia impunha seu domínio nas condições que desejava nem o proletariado parecia preparado para exercer a sua preponderância de classe.

Contrasta, no entanto, vivamente, a consciência do proletariado parisiense de 1871 com os seus legatários de 2021. Diversa é a postura desses legatários. Para eles, diferentemente dos testadores do século XIX, a questão do poder proletário e socialista não está posta. Às vezes, levantam-se, rebelam-se, insurgem-se. Use-se o termo que aprouver, diria algum filósofo, mas esses levantes, rebeliões e insurgências do século XXI não colocam em pauta o problema do poder. Lênin (2002) ensinou que fora do poder tudo é ilusão. Essa, contudo, não é a compreensão que alucina a consciência do proletariado. Esse, em linhas gerais, se encontra divorciado das suas antigas e célebres tradições. Por isso, sublevam-se contra os seus amos, mas não se propõem a quebrar sua máquina de opressão - o Estado - nem a romper com as relações sociais que lhe servem de esteio.

Os acontecimentos de fins dos anos 1980 e do começo da década imediatamente subsequente, que varreram os Estado operários burocráticos, cuja existência era tomada como o "socialismo real", imprimiram um ritmo avassalador à reação imperialista. Os ideólogos da burguesia, sem se corar de pudor, imediatamente trataram de difundir, não tão só a "morte do socialismo", mas, igualmente, a eternidade do domínio do capital. A exploração capitalista era escoimada, isto é, isentada de qualquer acusação ou deslize. A reação triunfava. E assim era definido o problema.

Compreende-se, então, o retrocesso que se processou na consciência de milhões de pessoas que, certamente, perderam qualquer referência além do domínio do capital. Esses esclarecimentos são necessários para afastar qualquer mal-entendido quando se imputa à consciência socialista uma viagem no tempo, um deslocamento a preceder o espírito ideológico que alimentou os insurrectos de Paris, em 1871 (QUEIROZ, 2017).

Pouco a pouco, todavia, os ecos ideológicos da dominação capitalista e os seus mitos quase indevassáveis começam a ruir juntamente com os seus ídolos. Escravistas, 
rainhas e conquistadores são julgados e entornam no chão das praças públicas. É uma lástima, porém, que as massas do povo ainda não vislumbrem a necessidade de ir além da contestação aos ecos, mitos e ídolos do capital que os colonizam e arruínam. Efetivamente, abriu-se um fosso entre ação e consciência. Há sempre um quê de crítica e resistência que esbarra nessa contradição de ferro.

Seria esse estado de coisas definitivamente perene e irreversível? Estaria a humanidade ante um fato absoluto? Ou, opostamente, as lutas em curso sinalizam em uma direção que não é do agrado dos capitalistas e apologetas do domínio burguês-imperialista? Essas são as cartas que estão na mesa. De quem é a vez de jogar?

Por enquanto, o jogo é jogado de um lado pelos vampiros capitalistas sedentos de sangue e de outro pela classe trabalhadora por meio de lutas de explícita resistência. Quando os diversos movimentos dos produtores da riqueza confluírem em uma onda mais abrangente, provavelmente, estar-se-á na presença de uma nova situação social e política, qualitativamente distinta.

O que até agora tem impedido que isso aconteça? Seguramente, não há um fator explicativo isolado. Quero, no entanto, chamar a atenção do que considero um dos fatores essenciais, qual seja, o obstáculo real constituído pelas direções políticas da classe trabalhadora, dos movimentos sociais e da juventude radicalizada, o que inclui o velho reformismo e o neorreformismo.

Um historiador ou um militante político escolado em Marx, como se sabe, tem a prática como critério da verdade. Chegando a haver, em contados casos, quem se dispõe a reunir os trabalhadores frente à crise capitalista, há de se admitir que a maioria navega em mares diametralmente opostos. Essa é a pedra angular que explica a conduta política das principais lideranças das lutas em curso. O espírito que as anima decorre de uma mítica fusão entre um reformismo sem reformas e uma mistificação do regime social capitalista. A unidade da velha cepa conservadora com as novas direções - que também negam o socialismo como estratégia e o tomam unicamente como um discurso de entono radical para fins eleitorais -, até certo ponto, esclarece o motivo de a Comuna ressurgir na condição de simples pré-ensaio ou lastimoso rascunho, um espectro poroso e não a expressão dramática e profunda de 150 anos de história dos expropriados. Mais do que isso: a Comuna que retoma o seu lugar no mundo mediante gestos e sonhos mal alinhavados, diante desse quadro brevemente insinuado, não consegue ir além de uma teatralização inconsequente. 
Esse é o enigma não resolvido da história. Da sua solução depende a transformação do pré-ensaio em um novo assalto aos céus. O ascenso desigual em curso, cujo epicentro parece ser a América do Sul, no átimo de tempo em que escrevo este texto, não engendra uma nova consciência política que nos leve a uma etapa histórica que, grosso modo, seria como reviver os anos que marcaram o advento da Comuna de Paris e, num sentido mais amplo, o da Revolução Russa (1917). Mas não há como sair do lugar sem levar em conta que as lutas sociais, ainda que em meio a uma pandemia, não deixaram de mostrar a cara. O vento dos conflitos sociais assaltou o mundo desde os Estados Unidos, e agora a Indoafro-Latino América parece que aceitou o convite e entrou na dança.

A questão é se o vento se transformará em vendaval, ou seja, qual será a intensidade e a amplitude dos embates de classe no próximo período. Chile, Bolívia, Peru, Colômbia e, pouco a pouco, até o Brasil estão no salão e dançam a canção das ruas, a despeito de todas as dificuldades de se manifestar sob o fogo cruzado da ofensiva econômica e da explosão da Covid-19.

A crise que se arrasta desde 2008 está no epicentro das ocorrências mais sentidas nos últimos anos. A pandemia não só aprofundou a crise, mas concedeu a ela uma dimensão inegavelmente mais complexa. Cresceu a fortuna dos ricos e a miséria das amplas massas da classe que vive da venda ou da pretensão da venda de sua força de trabalho e, junto disso, a insatisfação popular e a violência do Estado. Aqui, crise econômica, crise sanitária e comoção social se combinam de modo eloquente. Desde o começo da hecatombe econômica, aliada às graves circunstâncias da saúde pública, as pequenas explosões sociais se multiplicam, mas ainda são insuficientes e, algumas vezes, fragmentadas.

Ora, se a sociedade está diante de batalhas em potencial que envolve as suas classes fundamentais, causa estranheza se falar de um pequeno pré-ensaio de revolução social, pelo menos em alguns pontos da América do Sul? Mas não deveria haver estranhamento, também, na medida em que se ignora os sinais de descontentamento social?

Marx sempre procurou ouvir de onde viria o canto do galo. Hoje, provavelmente, ele aflora dos núcleos mais explorados e oprimidos do proletariado e das regiões economicamente mais dependentes, mas não só. A explosão da juventude negra iniciada nos EUA e que se espalhou no mundo não tem nenhuma mensagem a nos passar como humanos-humanas? Ora, reside precisamente aí o fato de que o destino da luta de classes não está divorciado do destino dessas explosões de raça e classe. 
$\mathrm{E}$ isso, em larga escala, me parece rigorosamente válido quando se aborda $\mathrm{o}$ tema de gênero. Numa rápida analogia histórica, como não associar a vigorosa manifestação das mulheres na Argentina, em fins de 2020, em torno da bandeira do aborto legal, e a descrição de Marx (2008, p. 426) de que "as mulheres de Paris (deram) jubilosamente as suas vidas nas barricadas e nos lugares de execução"?

Essas situações em si - com suas incontáveis manifestações e protestos exigem indagar: que programa pode potencializar as mobilizações em curso e as que podem explodir no seu rastilho?

Em 1871, Marx foi capaz de oferecer um programa e uma estratégia, que até hoje vibram nas páginas de A guerra civil em França e, presentemente, esse programa e estratégia aparecem frente ao tribunal da consciência proletária como uma resposta para ontem e não para os dias que ora se apresentam com os seus olhos vermelhos e nariz e boca vendados. Atualmente, as direções de milhões de almas penduradas em curtume, caetanamente falando, não poupam esforços de expulsar da memória dos pendurados tradições programáticas e estratégicas que alimentaram, e também foram nutridas, pela Comuna de Paris.

Sob essa perspectiva, a necessidade de se construir novas direções políticas, sob a base da unidade e independência de classe de trabalhadoras e trabalhadores em relação a todas as variantes de frente ampla - as antigas e as novas - segue como uma tarefa inegociável. Sem isso, parece-me, a Comuna persistirá como um sinal que se acende a cada explosão social apenas para mais adiante se apagar em uma expectativa de luta que nunca extrapola as linhas de fronteira do regime social existente.

A crise é imensa, mas sem o programa, a estratégia e a direção (da qual Marx é o primeiro referencial) que nutriram os comunards de 1871, os legatários do século XXI seguirão reféns do estratagema do vaga-lume - que ilumina a noite sem jamais conseguir ardê-la. Trata-se inevitavelmente de levantar o programa que se coaduna ao tempo atual e não ao de Marx, mas tendo em mente o corte de classe que ele esgrimiu e, junto dele, o governo da Comuna. Não é aleatório que ele tenha sido o primeiro governo operário da história.

Ainda que parcelas da vanguarda proletária estejam conscientes de que a infâmia indiæivel seja histórica e não eterna, há os que se contentam com a venda de facilidades e a esses não custaria muito se fiar nas orientações do velho Marx (2008, p. 408) para quem a emancipação dos trabalhadores e trabalhadoras depende de "longas lutas" e de "uma série de processos históricos que transformam circunstâncias e homens", conforme já 
assinalado. Se havia razões para se acreditar em tais palavras no século XIX, provavelmente não há por que não as tomar como criveis e necessárias nos alvores do século XXI, principalmente se se leva em conta a quadra atual e, mais do que isso, século e meio de experiência do movimento operário mundial. Sem essa compreensão, também, seguiremos todas e todos nós cegos frente à estratégia do vaga-lume.

Por fim, se o papel da luta de classes é também educativo, o cenário não tem, nem pode ter, uma permanente cerração como horizonte. A experiência da luta de classes e das massas trabalhadoras com as suas direções é condição sine qua non para que os despossuídos e o programa/estratégia da revolução não corram por linhas paralelas, mas voltem a se encontrar e engendrem, uma vez mais, uma força irresistível, o que depende da unidade "dos de baixo", de sua mobilização e do caráter dessa mobilização. Aí, e só aí, a Comuna será mais do que um simples ensaio ou mais do que uma grandiosa rememoração.

Sabe-se que o desemprego e a fome - resultantes da crise global e do encarecimento do preço dos produtos básicos, respectivamente - constituem aspectos da realidade que podem contribuir para o acirramento das relações entre as empresas e o Estado, de um lado, e os trabalhadores e trabalhadoras que, frente à desocupação e alta do custo da alimentação, aos poucos, podem vir a se enfileirarem do outro lado do traçado que, pouco a pouco, marca o chão da luta social. Com efeito, os estampidos da luta de classes tendem a se espalhar no rastro do mais agudo descontentamento. A classe trabalhadora começa a ter iniciativa social.

Junto com isso, essas explosões podem produzir formas alternativas de organização dos espoliados pelo capital, uma vez que, levados à fúria pela exploração desenfreada dos patrões, as camadas populares venham a adotar como seu o uso de métodos e ações nitidamente radicalizados. Quando a maré virar, esses métodos e atos radicalizados já estarão internalizados como parte da cultura de classe da massa trabalhadora em luta e, sem dúvida, poderão vir a cumprir um papel decisivo em embates de grau mais abrangente. Por isso, o precoce temor das classes dominantes ao se depararem com as fortes tendências de explosão social.

De feito, os trabalhadores seguem acreditando em saídas por dentro do regime social capitalista. Enquanto essa situação persistir, as possibilidades de uma nova comuna (à moda de Paris?) $)^{2}$ são quase nulas, dado que a consciência proletária permanece duradouramente reformista. Nos problemas fundamentais, a consciência do operariado

\footnotetext{
2 A Comuna de Paris foi algo novo em comparação às comunas medievais. Paris inspira, Paris instiga, mas não se repete. As comunas do século XXI haverão de vestir os próprios trajes. Apesar disso, cabe uma advertência histórica: as comunas, no sentido moderno, respondem a um ponto comum: o despotismo do capital e do Estado.
} 
continua praticamente no limiar anterior à crise humanitária, o que não quer dizer que elas (as massas) permaneçam no mesmo lugar. Sem dúvida, as rosas ilusões ainda não perderam o viço da última estação, apesar dos operários e dos pobres da periferia rilharem os dentes de raiva ante o peso da superexploração a que estão sujeitos.

Os socialistas, contudo, não podem se postar alheios aos pequenos e quase imperceptíveis avanços no plano da consciência de classe, ainda que no seu nível mais elementar. Insisto: quando a maré virar, consciência e ação podem ser guiadas numa só direção.

De fato, no terreno mais visível das coisas, o operariado se olha no espelho da história sem se reconhecer. É essa precisamente a imagem de uma consciência embebida de ilusões reformistas. Se nós marxistas estamos certos ao dizer que as ideias não caem do céu, não seria igualmente correto admitir que a mudança de qualidade no plano da consciência não cairá do céu, mas será forjada nas lutas em curso? E nisso há uma segunda vantagem política importante: a de não sucumbir ante as dificuldades.

Do ponto de vista das amplas massas, é sob o impulso da luta de classes que algumas das lições mais importantes são aprendidas. À moda de Lênin, trata-se de uma fórmula indigesta, mas necessária e prática.

Não se pode esquecer que o capitalismo rebaixa os homens e as mulheres ao seu nível mais tacanho e isso não é diferente no que toca à consciência das classes subalternas. Em tempo de reação ideológica, essa questão se torna desdenhosamente mais complexa, severa e desatinada. Apesar disso, não se constrói o novo mundo sem os homens, as mulheres e os materiais com os quais ambos se relacionam ainda que sob a égide infernalmente nefasta do domínio do capital. Essa é a condição para que a Comuna do século XXI possa, enfim, triunfar.

Tarjados de linhas convergentes, os movimentos proletários, de ontem e de hoje, importa assinalar, são emissões obstinadas de uma resistência de classe, de uma cultura de classe e de uma luta de classes. Urge, para que avancem e se consolidem, que se retifiquem as orientações que, hoje, são majoritárias na prática e consciência de milhões de trabalhadores, que se desesperam entre a retirada de direitos e a ameaça de que a fome avance perigosamente nas fileiras da classe que vive do trabalho (ou que, pelo menos, dele deveria viver). Fora daí, não há sonho possível de uma nova Comuna. No fundo, a ameaça de escassez e a escassez repetida unem trabalhadoras e trabalhadores de continentes, histórias e culturas aparentemente muito díspares. 
Há muito ceticismo, mas nunca é demais advertir aos céticos: as Comunas não são sonhos proibidos e todos sabem o que pode acontecer com um sonho que se sonha junto.

\section{CONSIDERAÇÕES FINAIS}

Os trabalhadores e trabalhadoras parecem dominados por um forçado e permanente retraimento e subjugados às raias que são designadas e impostas pelas classes dominantes e o seu regime político. Em suas ramificações internas, entretanto, começaram a cruzar o fio do seu canto. Para não renunciar à velha metáfora, diria que o galo começou a cantar, mas nem todos ouviram. É um canto tênue, mas do Pacífico ao Atlântico, do Chile ao Brasil, dos Estados Unidos à França, da Tailândia à Polônia, ele já não é cantado sozinho. Nessas circunstâncias, frente a rebeldia dos fatos, o que dirão os que julgam a Comuna uma simples rememoração sem volta?

A comuna de hoje não será idêntica à de ontem, mas será igualmente uma comuna, em que a "veneração supersticiosa do Estado", de que falava Engels (2008, p. 354), dará lugar a uma república genuinamente social. 


\section{Referências}

BARSOTTI, P.; LERNER, F; ORSO, J. P. (Orgs.). A Comuna de Paris de 1871 - história e atualidade. São Paulo: Ícone Editora, 2002.

BOITO JR., Armando (Org.). A Comuna na História. São Paulo: Xamã-Cemarx/IFCH, 2001.

CHAUVEL, Louis. Classes e gerações: a insuficiência das hipóteses da teoria do fim das classes. Crítica Marxista, São Paulo: Boitempo, n. 15, 2002.

COGGIOLA, Osvaldo (org.). Escritos sobre a Comuna de Paris - introdução, São Paulo: Xamã, 2002.

ENGELS, F. Introdução. In: MARX, K.; ENGELS, F. A guerra civil na França. São Paulo: Expressão Popular, 2008.

FERLINI, Vera Lúcia Amaral. História e revolução. Atualidade de uma relação. In: COGGIOLA, Osvaldo. História e revolução. São Paulo: Xamã/FFLCH, 1998.

GONZÁLES, Horácio. A Comuna de Paris: os assaltantes do céu. São Paulo: Brasiliense, 1999.

HOBSBAWM, Eric. Sobre história. São Paulo: Companhia das Letras, 1998.

LENIN, V. U. O imperialismo - fase superior do capitalismo. São Paulo: Centauro, 2002.

LIGASSARAY, Proper Olivier. História da Comuna de 1871. São Paulo: Ensaio, 1991.

MARX, Karl. A guerra civil na França. In: MARX, Karl. A revolução antes da revolução. São Paulo: Expressão Popular, 2008.

. 018 brumário e Cartas a Kugelmann. Rio de Janeiro: Paz e terra, 1997.

MATOS, Marcelo Badaró. A Comuna de Paris no Brasil. Revista Outubro, n. 06, São Paulo: Instituto de Estudos Socialistas, 2002.

QUEIROZ, Fábio José de. Sete questões sobre a restauração capitalista no Leste Europeu. In: SILVA, Michel Goulart. Revolução russa: passado e presente. São Paulo: Todas as Musas, 2017.

SENA JUNIOR, Carlos Zacarias. A Comuna de Paris e a questão da transição: o primeiro ensaio da revolução permanente. In: PINHEIRO, Milton (Org.). 140 anos da Comuna de Paris. São Paulo: Outras Expressões, 2011.

TROTSKI, Leon. A Comuna de Paris, Brasília: Edições Centelha Cultural, São Paulo: Iskra, 2011. 
Recebido em: 14/06/2021

Aceito em: 20/07/2021.

Publicado online em: 20/07/2021 